\title{
Gender differences in left ventricular geometry and determinants of myocardial perfusion reserve in patients with severe aortic stenosis
}

\author{
Christopher D Steadman ${ }^{1 *}$, Michael Jerosch-Herold ${ }^{2}$, Benjamin Grundy ${ }^{3}$, Suzanne Rafelt ${ }^{1}$, Leong L Ng${ }^{1}$, \\ lain B Squire', Nilesh J Samani', Gerry P McCann ${ }^{1}$
}

From 2011 SCMR/Euro CMR Joint Scientific Sessions

Nice, France. 3-6 February 2011

\section{Objectives}

The aim of this analysis was to look at the impact of gender on LV geometry and the predictors of myocardial perfusion reserve (MPR) in severe aortic stenosis (AS).

\section{Background}

It is well recognised that cardiac size is different between the two genders, even when corrected for body size. In AS echocardiographic studies suggest women have higher relative wall thickness and better preserved left ventricular (LV) ejection fraction (EF). There are little cardiac magnetic resonance (CMR) data on gender differences in severe AS, in particular MPR.

\section{Methods}

Forty-one patients with isolated severe AS without obstructive coronary artery disease underwent adenosine stress perfusion CMR in a $1.5 \mathrm{~T}$ scanner (Siemens Avanto); MPR was calculated from absolute myocardial blood flow during adenosine hyperaemia and rest determined by model-independent deconvolution of signal intensity curves with an arterial input function. Transthoracic echocardiography was used to assess AS severity, tissue Doppler derived diastolic function, LVRPP (LV rate pressure product $=[$ systolic blood pressure (SBP) + peak aortic valve gradient]"heart rate) an estimate of myocardial work, and diastolic perfusion time (DPT $=[\mathrm{R}-\mathrm{R}$ interval - LV ejection time]"heart rate).

\section{Results}

Females were older with significantly lower body surface area (BSA) and higher SBP. Despite equivalent AS severity females had significantly lower LV mass index (LVMI), LV volumes and wall thickness (relative and absolute), less late gadolinium enhancement (LGE) and higher EF. Resting and hyperaemic myocardial blood flow (MBF) were higher in females although MPR remained the same. Results are summarised in Tables 1

\section{Table 1 Demographics and Echocardiographic Data}

\begin{tabular}{lllll}
\hline Variable & Whole group $(\mathbf{n}=\mathbf{4 1})$ & Male $(\mathbf{n}=\mathbf{3 1})$ & Female $(\mathbf{n}=\mathbf{1 0})$ & Male vs. Female $\mathbf{p}$-value \\
\hline Age & $66 \pm 8$ & $64 \pm 8$ & $72 \pm 8$ & $0.018^{*}$ \\
BSA $(\mathrm{m} 2)$ & $1.92 \pm 0.21$ & $1.98 \pm 0.18$ & $1.71 \pm 0.14$ & $0.001^{*}$ \\
SBP(mmHg) & $130 \pm 19$ & $126 \pm 15$ & $144 \pm 23$ & $0.008^{*}$ \\
Peak aortic velocity (AV)(m/s) & $4.42 \pm 0.58$ & $4.45 \pm 0.60$ & $4.33 \pm 0.52$ & 0.564 \\
Mean PG(mmHg) & $47.9 \pm 14.3$ & $48.6 \pm 15.0$ & $45.9 \pm 12.2$ & 0.604 \\
Aortic valve area index (AVAl) (cm2/m2) & $0.46 \pm 0.13$ & $0.44 \pm 0.10$ & $0.50 \pm 0.20$ & 0.219 \\
LVRPP(mmHg.bpm.10-4) & $1.51 \pm 0.28$ & $1.47 \pm 0.29$ & $1.64 \pm 0.19$ & 0.101 \\
Resting DPT(s/min) & $37.8 \pm 4.0$ & $38.4 \pm 3.7$ & $35.8 \pm 4.2$ & 0.074 \\
Septal E/E' & $14.1[12.2-18.6]$ & $12.9[10.9-18.4]$ & $16.2[15.2-18.9]$ & 0.052
\end{tabular}

${ }^{1}$ Department of Cardiovascular Sciences, University of Leicester, Leicester, UK 
Table 2 CMR Data

\begin{tabular}{lllll}
\hline Variable & Whole group $(\mathbf{n}=\mathbf{4 1})$ & Male $(\mathbf{n}=\mathbf{3 1})$ & Female(n=10) & Male vs. Female $\mathbf{p}$-value \\
\hline LVMI (g/m2) & $68.9 \pm 17.9$ & $74.1 \pm 16.3$ & $52.8 \pm 12.5$ & $0.001^{*}$ \\
LV end-diastolic volume index (LVEDVI) $(\mathrm{mL} / \mathrm{m} 2)$ & $96.4 \pm 15.2$ & $99.8 \pm 13.5$ & $85.8 \pm 16.0$ & $0.009^{*}$ \\
LVM/LVEDV(g/mL) & $0.72 \pm 0.15$ & $0.74 \pm 0.14$ & $0.62 \pm 0.13$ & $0.025^{*}$ \\
LVEF(\%) & $56.4 \pm 6.5$ & $54.9 \pm 6.8$ & $60.5 \pm 5.0$ & $0.022^{*}$ \\
Maximum wall thickness(mm) & $13.2 \pm 2.5$ & $13.8 \pm 2.4$ & $11.1 \pm 1.4$ & $0.002^{*}$ \\
Resting MBF(mL/min/g) & $0.90 \pm 0.20$ & $0.84 \pm 0.15$ & $1.06 \pm 0.24$ & $0.001^{*}$ \\
Hyperaemic MBF(mL/min/g) & $1.77 \pm 0.47$ & $1.64 \pm 0.38$ & $2.15 \pm 0.53$ & $0.002^{*}$ \\
MPR & $2.03 \pm 0.55$ & $2.01 \pm 0.53$ & $2.09 \pm 0.63$ & 0.674 \\
LGE present & $23(56 \%)$ & $21(68 \%)$ & $2(20 \%)$ & $0.012^{*}$ \\
\hline
\end{tabular}

Table 3 Correlations with MPR

\begin{tabular}{lllll}
\hline Variable & Male Beta & Male p-value & Female Beta & Female p-value \\
\hline Peak AV & -0.349 & 0.059 & -0.361 & 0.324 \\
Mean PG & -0.277 & 0.136 & -0.524 & 0.158 \\
AVAl & 0.258 & 0.165 & 0.098 & 0.807 \\
LVMI & -0.495 & $0.005^{*}$ & -0.348 & 0.340 \\
LVM/LVEDV & -0.477 & $0.008^{*}$ & -0.105 & 0.842 \\
LGE & -0.332 & 0.071 & -0.629 & 0.071 \\
LVRPP & -0.103 & 0.595 & 0.768 & 0.093 \\
DPT & -0.340 & 0.078 & -0.521 & 0.136 \\
Septal E/E' & -0.527 & $0.004^{*}$ & -0.227 & 0.545
\end{tabular}

and 2. Variables with the strongest correlation with MPR in females were mean pressure gradient (PG), LGE, LVRPP, and DPT in contrast to LV mass, relative wall thickness and septal E/E' in males, Table 3.

\section{Conclusions}

These findings confirm the gender differences in LV geometry in response to pressure overload. The factors contributing to microvascular dysfunction also appear to be different. In males increased LV mass and relative wall thickness with associated diastolic dysfunction appear to be important determinants of microvascular dysfunction, in contrast to females where pressure gradients and diastolic perfusion time play a larger role. Paradoxically LVRPP was positively correlated with MPR in females. These differences may have implications for the treatment of microvascular dysfunction in females compared with males.

\section{Author details}

${ }^{1}$ Department of Cardiovascular Sciences, University of Leicester, Leicester, UK. 2Department of Radiology, Brigham \& Women's Hospital and Harvard Medical School, Boston, MA, USA. ${ }^{3} \mathrm{NIHR}$ Leicester Cardiovascular Biomedical Research Unit, Leicester, UK.

Published: 2 February 2011
doi:10.1186/1532-429X-13-S1-041

Cite this article as: Steadman et al:: Gender differences in left ventricular geometry and determinants of myocardial perfusion reserve in patients with severe aortic stenosis. Journal of Cardiovascular Magnetic Resonance 2011 13(Suppl 1):041.
Submit your next manuscript to BioMed Central and take full advantage of:

- Convenient online submission

- Thorough peer review

- No space constraints or color figure charges

- Immediate publication on acceptance

- Inclusion in PubMed, CAS, Scopus and Google Scholar

- Research which is freely available for redistribution

Submit your manuscript at www.biomedcentral.com/submit
C Biomed Central 